\title{
Propriedades da argamassa modificada com polímeros redispersíveis de etileno-acetato de vinila (EVA)
}

\author{
Properties of vinyl acetate-ethylene modified mortar \\ (VAE)
}

\section{Karen Sorgi Bomediano \\ Carlos Eduardo Marmorato Gomes \\ Patrícia Stella Pucharelli Fontanini}

\section{Resumo}

A

baixa capacidade de absorção de energia das argamassas cimentícias resulta na formação de microfissuras e, consequentemente, influencia diretamente sua durabilidade. Em situações como reparos estruturais, as argamassas necessitam de características especiais, tais como menor retração hidráulica, maior deformabilidade e elevada aderência. O uso de polímeros redispersíveis, ou em emulsões, na modificação de argamassas cimentícias tem sido frequente, porém tais adições podem influir distintamente em suas propriedades. De forma geral, os polímeros termoplásticos podem aumentar a vida útil da argamassa, em especial, devido à redução de seu módulo de deformação e, consequentemente, de sua fissuração. Nesse sentido, foi analisada a aplicação de dois copolímeros redispersíveis à base de etileno-acetato de vinila para verificar sua influência no estado fresco e endurecido das argamassas e sua possível aplicação em reparos estruturais. Foram realizados ensaios de consistência, resistência mecânica, índices físicos e microscopia óptica. Os resultados evidenciam que o emprego desses copolímeros reduz a absorção de água devido à formação do filme polimérico e a sua coalescência nos poros. Ademais, os copolímeros proporcionam maior plasticidade das argamassas e reduzem seu módulo de deformação, características importantes para aplicações especiais como reparos estruturais em pisos de concreto armado.

Palavras-chave: Polímero redispersível. Argamassa modificada. Etileno-acetato de vinila.

${ }^{1}$ Karen Sorgi Bomediano ${ }^{1}$ Universidade Estadual de Campinas Campinas - SP - Brasil

${ }^{2}$ Carlos Eduardo Marmorato Gomes ${ }^{2}$ Universidade Estadual de Campinas Campinas - SP - Brasil

${ }^{3}$ Patrícia Stella Pucharelli Fontanini ${ }^{3}$ Universidade Estadual de Campinas Campinas - SP - Brasil

Recebido em 23/09/19 Aceito em 05/04/20

\begin{abstract}
The lower energy absorption of cementitious mortars results in high level of cracks and it directly influences the durability of these composites. To applications as structural repairs, Portland cement mortars require special properties such as lower shrinkage, high deformability level and good adhesion strength. Redispersible or emulsion polymers can distinctly influence the fresh and hardened state of these composites. In general, thermoplastic polymers can improve the performance of mortars, especially due to elastic modulus reduction and, consequently, the crack formations. In this way, this study verify the application of two redispersible copolymers based on vinyl acetate and ethylene in order to verify their influence on fresh and hardened state of mortars and the possible application of these composites in structural repair. Consistency, mechanical strength, physical properties and optical microscopy tests were performed. The results show that the copolymer additions reduce the water absorption due to the polymeric film formation and its coalescence into the pores. In addition, the copolymers provide higher mortar plasticity and decrease the elastic modulus of the mortars studied being its behavior important to structural repairs as in concrete floors.

Keywords: Polymer powders. Polymer modified mortar. Vinyl acetate ethylene.
\end{abstract}




\section{Introdução}

As manifestações patológicas e os problemas de deterioração das estruturas de concreto podem ser oriundos de fenômenos físicos ou químicos e, para restabelecimento de seu desempenho, implicam a necessidade de adoção de um sistema de restauro. Para essa finalidade, as argamassas convencionais podem apresentar problemas de durabilidade, especialmente devido a falhas de aderência e fissuras de retração hidráulica nas idades iniciais (AHMED, 2011). Além disso, as argamassas convencionais, não modificadas, apresentam baixa capacidade de absorção de energia, que induz sua microfissuração e pode prejudicar sua vida útil.

O módulo de deformação de uma argamassa está diretamente associado aos materiais empregados, ao processo produtivo e a sua aplicação. Nesse sentido, são variáveis o tipo e o teor dos aglomerantes e dos agregados empregados, a quantidade de água e fatores relacionados à sua produção e aplicação, como teor de ar incorporado, adensamento e compacidade. Em condições de serviço, o desempenho mecânico desses compósitos também é resultante das tensões de aderência entre a matriz aglomerante e suas interfaces, como, por exemplo, agregados ou substratos. Nas regiões denominadas zonas de transição interfacial (ZTI), há maior concentração de produtos frágeis oriundos da hidratação do cimento Portland, como o hidróxido de cálcio, podendo, portanto, apresentar maior fissuração, permeabilidade e ataque de agentes agressivos externos.

Nesse sentido, o uso de polímeros pode melhorar as propriedades físicas e mecânicas da argamassa de restauro. Basicamente, o sistema pode ser entendido como resultante da combinação de uma matriz inorgânica (cimento) e de uma matriz orgânica (polímero). Assim, essa modificação pode resultar na redução de seu módulo de deformação e, portanto, permitir maior tenacidade ao material. Ainda, como observado na literatura (OHAMA, 1995, 1998; MEDEIROS; HELENE; SELMO, 2009; RAMLI; TABASSI, 2012, 2013; WENG, 2017), as argamassas modificadas tendem a apresentar melhor aderência aos substratos, menor retração e absorção de água, alta resistência química e menor tempo de cura, propiciando, assim, características desejáveis para essa aplicação e garantindo, também, durabilidade superior às argamassas convencionais. A adição de polímeros também pode melhorar o desempenho da ZTI, agindo como ponte entre a matriz cimentícia e os agregados (AHMED, 2011). Nesse sentido, ganhos de resistência à tração e de tenacidade podem ser observados.

$\mathrm{Na}$ construção civil, o uso dos polímeros se iniciou nos anos 1950 e seu consumo vem aumentando gradativamente (MEHTA; MONTEIRO, 2014). De forma geral, a adição de polímeros em argamassas cimentícias possui por finalidade modificar suas propriedades tanto no estado fresco quanto no estado endurecido. Essas propriedades são afetadas por diversos fatores, como tipo e quantidade de polímero utilizado, teor de ar incorporado e condições de cura (OHAMA, 1998). Dentre os polímeros mais usados, destacam-se os copolímeros à base de etileno-acetato de vinila (EVA), pois apresentam boa resistência ao intemperismo e maior durabilidade em meio alcalino.

Sabe-se também que os polímeros se relacionam física e quimicamente com os compósitos cimentícios e que essas interações ocorrem com a formação do filme polimérico durante o processo de hidratação do cimento (SU; SUJATA, 1996; SILVA; ROMAN; GLEIZE, 2002; GOMES; FERREIRA; FERNANDES, 2005; SILVA; ROMAN, 2008). A facilidade para a formação do filme polimérico é também importante, pois pode influenciar diretamente a microestrutura da zona de transição, entre a pasta de cimento e os agregados (SAKAI; SUGITA, 1995). Normalmente, a formação do filme precede a hidratação do cimento, assim as partículas de polímero coalescem e preenchem os poros existentes, revestindo os grãos de cimento anidros e as partículas de agregados; no entanto, esse preenchimento dos vazios só é possível porque as partículas poliméricas são menores que as partículas de areia e de cimento.

A presença de EVA retarda as reações de hidratação do cimento (SILVA; ROMAN; GLEIZE, 2002); sendo assim, a camada formada pelo polímero se torna eficaz para o período de cura, pois ajuda a reter a água nos poros, colaborando para o processo de hidratação. Nesse sentido, é possível reduzir as fissuras de retração hidráulica.

No estado fresco, a adição de um polímero pode aumentar a plasticidade, melhorar a trabalhabilidade das argamassas e evitar o fenômeno de ressecamento. Consequentemente, ocorre um aumento da viscosidade das argamassas na fase líquida, devido ao efeito de vedação provocado pela formação de filmes muito finos e impermeáveis (OHAMA, 1998).

No estado endurecido, o uso de polímeros em argamassas cimentícias pode possibilitar incrementos de resistência à compressão e à tração (MARANHÃO; JOHN, 2009). O módulo de deformação da argamassa é reduzido (RIBEIRO; GONÇALVES; BRANCO, 2008),fazendo com que o compósito tenha maior 
capacidade de absorção de energia e, provavelmente, apresente melhor desempenho e menor fissuração (WANG; WANG, 2011).

Portanto, o presente estudo teve por objetivo verificar a influência de copolímeros redispersíveis à base de EVA nas propriedades do estado fresco e endurecido de argamassas, especialmente a resistência à compressão e o módulo de deformação, com foco em aplicações da construção civil, em que se exige maior flexibilidade para os reparos estruturais, como, por exemplo, para pisos estruturais de concreto.

\section{Materiais e método}

\section{Materiais}

Os materiais utilizados na preparação das argamassas são apresentados na Figura 1.

O agregado miúdo empregado foi a areia normal, proveniente do Instituto de Pesquisas Tecnológicas (IPT) e adicionada em 4 granulometrias diferentes - areia fina $\mathrm{n}^{\circ} 100(25 \%)$, média-fina $\mathrm{n}^{\circ} 50(25 \%)$, média-grossa $\mathrm{n}^{\circ} 30(25 \%)$ e grossa $\mathrm{n}^{\circ} 16(25 \%)$-para compor uma distribuição granulométrica contínua. O volume de argamassa foi calculado para um total de 36 corpos de prova cilíndricos de dimensão $5 \mathrm{~cm}$ x $10 \mathrm{~cm}$, sendo o consumo de cimento utilizado de $630 \mathrm{~kg} / \mathrm{m}^{3}$.

Apesar de terem a mesma base, os copolímeros utilizados apresentam diferentes características tensoativas e, consequentemente, comportamentos distintos. A Tabela 1 exibe as características dos copolímeros utilizados.

Figura 1 - Infográfico dos materiais utilizados

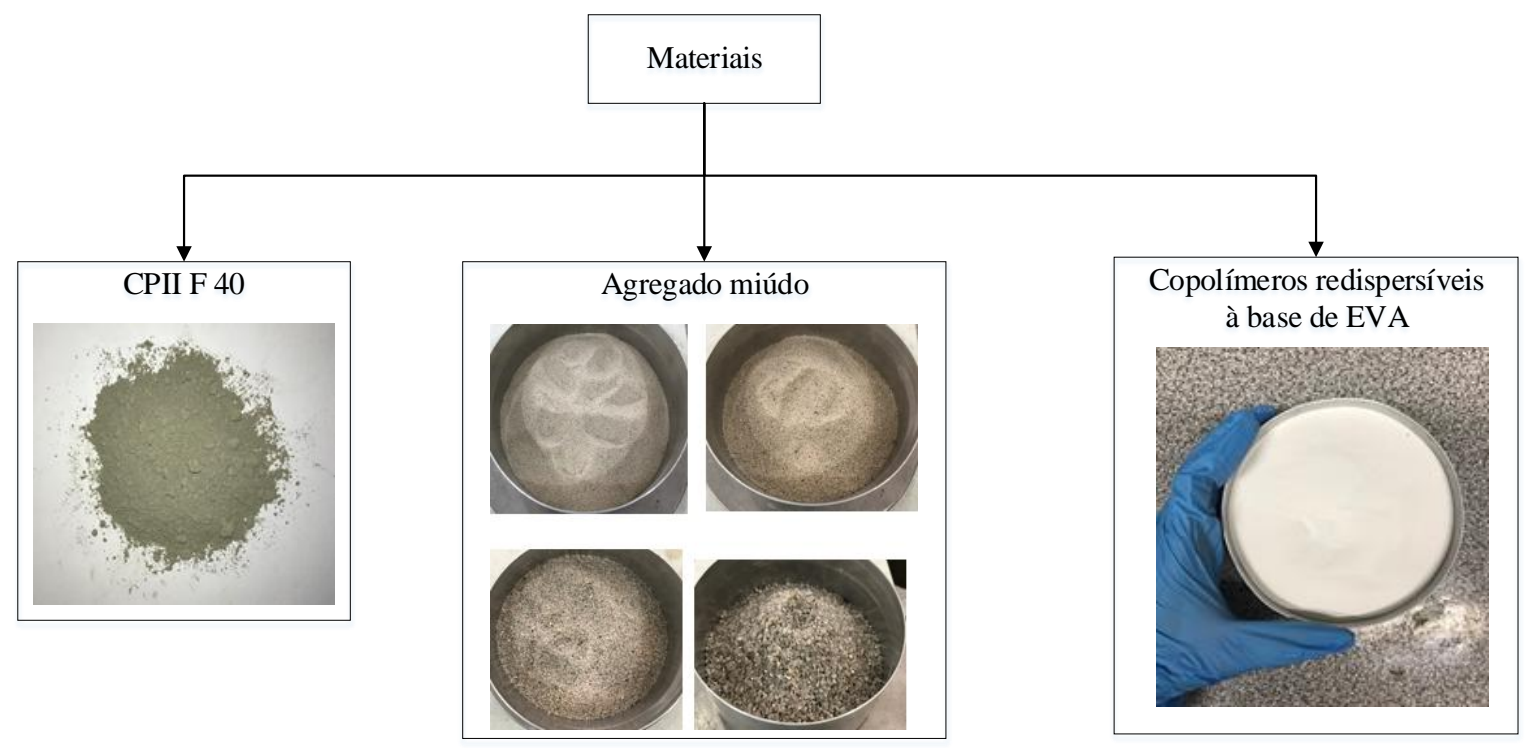

Tabela 1 - Propriedades do copolímero EVA

\begin{tabular}{c|c|c}
\hline Propriedades do copolímero & Polímero A & Polímero B \\
\hline Teor de sólidos $(\%)$ & $99 \pm 1$ & $99 \pm \pm$ \\
Densidade $\left(\mathrm{g} / \mathrm{cm}^{3}\right)$ & $0,49-0,59$ & $0,40-0,55$ \\
Tamanho da partícula & $0,5-8 \mu \mathrm{m}$ & $1-7 \mu \mathrm{m}$ \\
Coloide protetor & Álcool polivinílico & Álcool polivinílico \\
Temperatura mínima de formação de filme & $4{ }^{\circ} \mathrm{C}$ & $0{ }^{\circ} \mathrm{C}$ \\
\hline
\end{tabular}

Fonte: Wacker (2019). 


\section{Procedimento experimental}

Conforme apresentado no infográfico (Figura 2), para o procedimento experimental, foram realizados ensaios no estado fresco e endurecido, como índice de consistência da argamassa, módulo de deformação, resistência à compressão axial, absorção, índice de vazios, massa específica e microscopia óptica.

Primeiramente, foi realizada uma pré-homogeneização do cimento com o polímero EVA e, logo após, acrescentaram-se areia e água à mistura, que foi feita mecanicamente em uma argamassadeira a 1.500 RPM. Foram moldados 36 corpos de prova cilíndricos com dimensão de $5 \mathrm{~cm}$ x $10 \mathrm{~cm}$, relação a/c fixa de 0,50 e diferentes teores dos copolímeros sobre a massa de cimento (s.p.c.) (0\%, 1,5\%, 3\%, 6\% e 12\%), sendo, posteriormente, submetidos à cura ambiente por um período de 28 dias. Para cada teor de EVA, moldaramse 4 corpos de prova, totalizando 16 amostras para cada tipo de polímero (A e B) e 4 amostras para a argamassa sem adição. Utilizou-se um traço em massa de 1:2, que representa um teor de argamassa comumente empregado na produção de concretos para pisos industriais.

O fluxograma (Figura 3) indica como os procedimentos específicos foram conduzidos.

A consistência das argamassas foi verificada por meio de mesa de abatimento, sendo as análises realizadas conforme procedimentos prescritos na NBR 13276 (ABNT, 2016).

Os resultados da compressão axial aos 28 dias foram obtidos pela média aritmética de 4 corpos de prova, ensaiados de acordo com a NBR 7215 (ABNT, 1997), e os valores do módulo de deformação aos 28 dias, pela média aritmética de 3 corpos de prova, mínimo exigido pela NBR 8522 (ABNT, 2017). Utilizaram-se as amostras dos ensaios mecânicos para a realização dos ensaios de índices físicos, os quais foram feitos aos 28 dias, de acordo com a NBR 9778 (ABNT, 2009). Ademais, após os 28 dias, foram realizadas imagens de microscopia óptica com os fragmentos das amostras existentes para observar a quantidade de vazios nas argamassas e a possível presença de EVA.

Figura 2 - Infográfico das propriedades analisadas

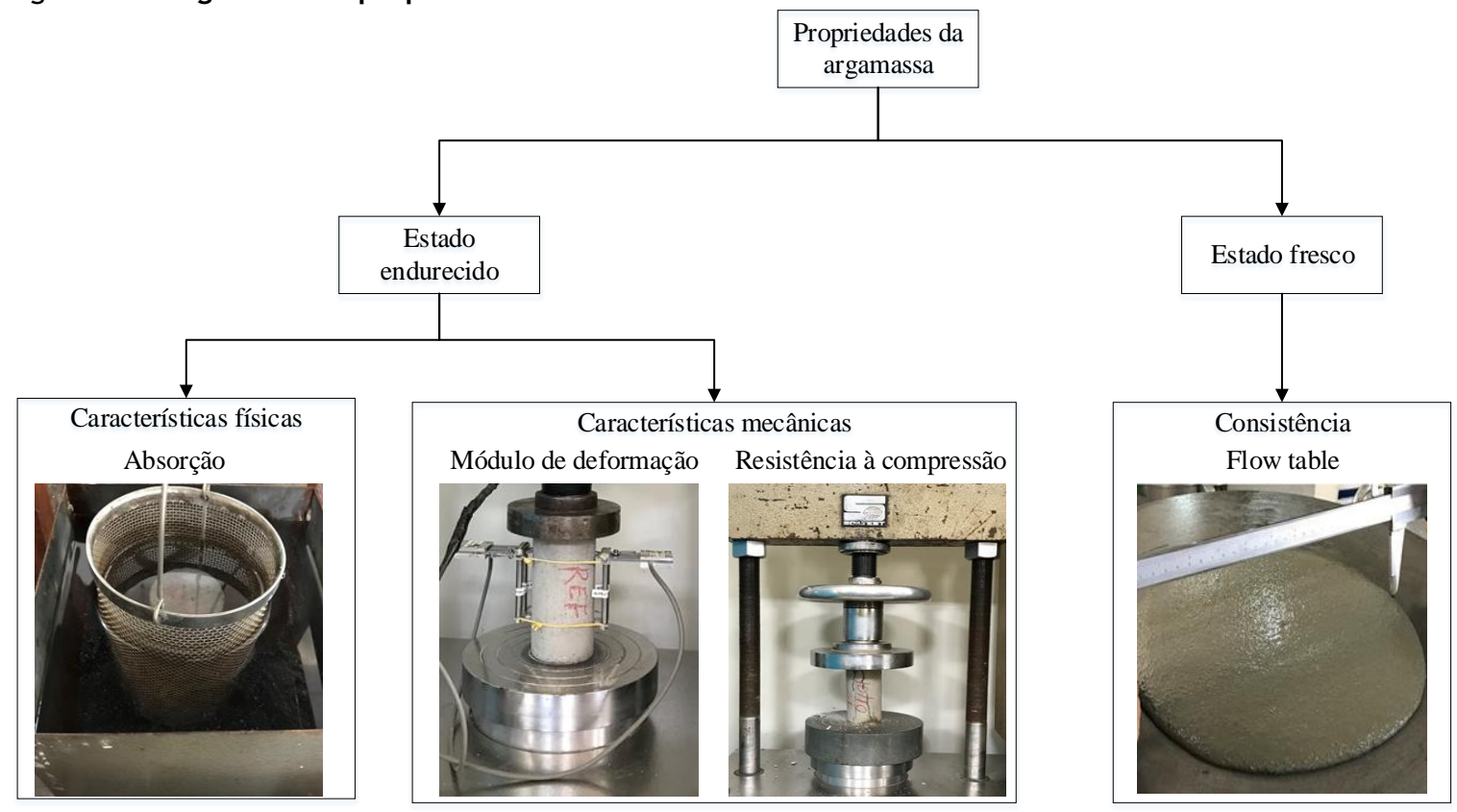

Figura 3 - Fluxograma

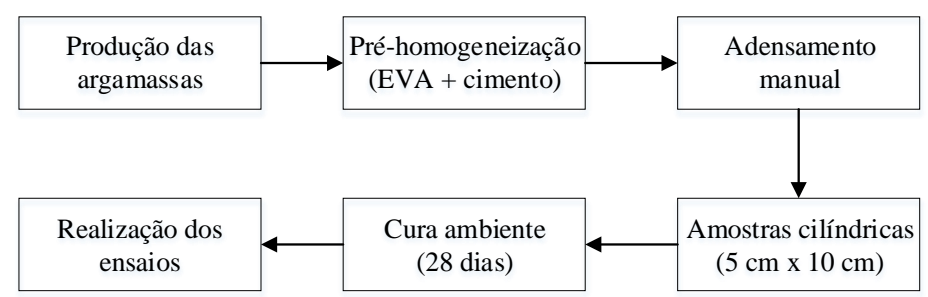

422 Bomediano, K. S.; Gomes, C. E. M.; Fontanini, P. S. P. 


\section{Resultados e discussões \\ Índice de consistência da argamassa}

Em conformidade com a literatura (OHAMA, 1998), verificou-se um aumento no índice de plasticidade das argamassas conforme o aumento do teor dos copolímeros A e B (Figura 4).

Notou-se que o copolímero A obteve maior espalhamento em relação ao copolímero B. Isso pode ser explicado pelo aumento no teor de ar incorporado devido à adição de EVA, pois a incorporação de microbolhas de ar diminui o atrito entre grãos e aumenta o índice de consistência da argamassa. Porém, essa incorporação pode influenciar suas propriedades mecânicas, tais como resistência à compressão e módulo de deformação (RAMLI; TABASSI, 2012).

Embora constituídos por monômeros de EVA, os copolímeros empregados possuem diferenças na relação entre monômeros que implicam diferentes pontos de amolecimento e ação surfactante.

De forma ilustrativa, as imagens de microscopia óptica mostram a porosidade e vazios presentes nas argamassas modificadas (Figuras 8 e 9).

Os resultados obtidos estão em consonância com os apresentados por Betioli et al. (2012), que relacionam o aumento da plasticidade e do índice de consistência das argamassas modificadas à ação das partículas poliméricas como esferas, à incorporação de ar e ao efeito de dispersão causado pela ação surfactante dos polímeros nos primeiros minutos de hidratação do cimento Portland.

\section{Índices físicos}

As argamassas modificadas apresentaram menor absorção de água nos teores acima de 3\% de EVA (Figura 5a). Para o menor teor de polímero $(1,5 \%)$, possivelmente ocorreu incorporação de ar, gerada pela adição do EVA. Porém, a quantidade de polímero não foi suficiente para a selagem parcial dos poros, justificando os valores maiores quando comparados aos da argamassa de referência. Nota-se que, para os maiores teores de polímero (6\% e 12\%), a absorção foi menor, pois, apesar do possível aumento da incorporação de ar, esses poros foram selados pela coalescência do polímero.

Essa menor permeabilidade está atribuída ao fato de as partículas de polímeros serem menores que os grãos de areia e de cimento, preenchendo pequenos vazios e eventualmente coalescendo em um filme polimérico que envolve o agregado e as partículas de cimento (RAMLI; TABASSI, 2012). O filme polimérico formado apresenta uma estrutura monolítica que é responsável pela ligação entre o polímero e a matriz, melhorando as características mecânicas e de durabilidade (AFRIDI et al., 2003).

Apesar da redução da massa específica das argamassas pela incorporação de ar e pelo poder surfactante dos polímeros, esses poros são parcialmente selados pelo filme polimérico; portanto, não se observou aumento no índice de vazios pelo método aplicado.

\section{Figura 4 - Avaliação da consistência da argamassa modificada com EVA pelo ensaio do flow table}

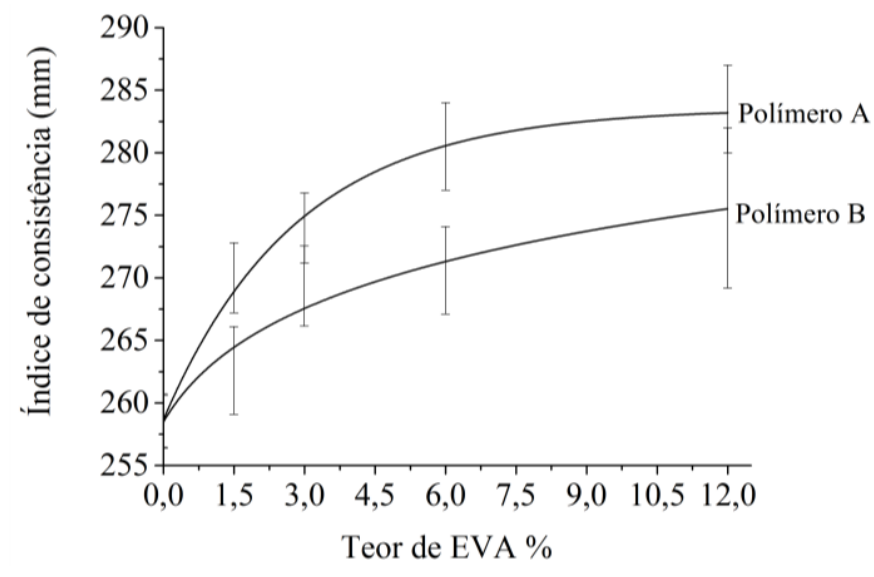


Figura 5 - Índices físicos aos 28 dias das argamassas modificadas com EVA

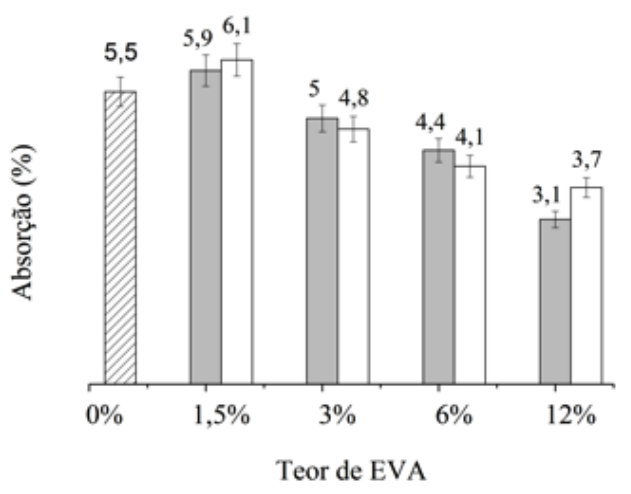

(a) Absorção

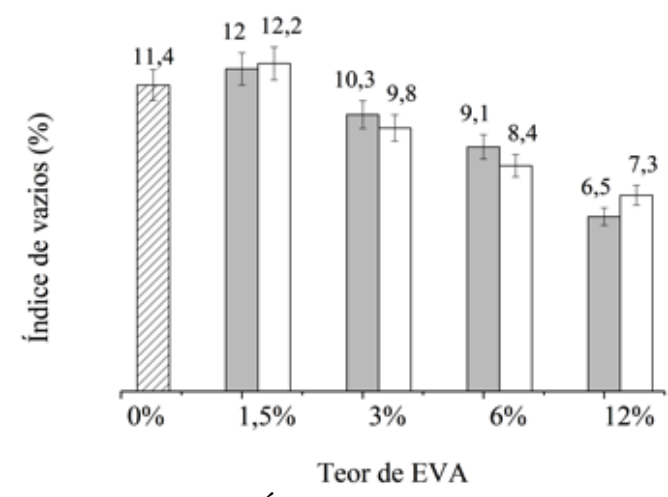

(b) Índice de vazios

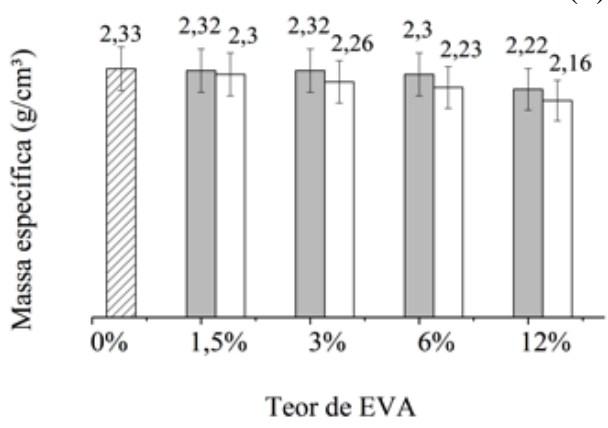

(c) Massa específica

Nota: Legenda:

Referência

Polímero A

Polímero B

\section{Resistência à compressão axial e módulo de deformação}

Os resultados mecânicos mostraram que houve redução nos valores de resistência à compressão e, consequentemente, no módulo de deformação das argamassas modificadas quando comparados aos de referência (Figura 6).

Para o teor máximo de polímero adotado (12\%), verificou-se uma redução da resistência à compressão $(7,9 \%$ e $22,4 \%)$ e do módulo de deformação $(22,7 \%$ e $24,1 \%)$ nas argamassas A e B, respectivamente. Adotando-se uma distribuição de probabilidade $t$ de Student, a redução de resistência à compressão para um nível de confiança de $95 \%$ foi de 18,3\% e 19,0\% e, para o módulo de deformação, de 27,6\% e 4,1\%, respectivamente. Provavelmente, para esse teor, houve maior incorporação de ar, também justificada pela menor densidade das argamassas modificadas e pelas imagens de microscopia ótica. $\mathrm{O}$ aumento da porosidade nos compósitos faz com que haja redução de sua resistência mecânica, podendo, portanto, influenciar outras propriedades do estado endurecido.

Para o copolímero A, contrapondo-se os menores teores de 1,5\%, 3\% e 6\%,ocorreram melhores propriedades mecânicas das argamassas. Possivelmente, nesses teores, a incorporação de microbolhas de ar permitiu melhor adensamento dessas argamassas.

Apesar de comportamento análogo, as argamassas que empregaram o copolímero B apresentaram sempre resultados inferiores às argamassas que adotaram o copolímero $\mathrm{A}$, bem como mostraram maior desvio padrão dos resultados. Novamente, ao considerar uma distribuição de probabilidade t de Student e um nível de confiança de $95 \%$, as relações de resistência à compressão entre as composições A e B a se considerar são de $31,8 / 26,6,29,6 / 20,8,25,6 / 17,4$ e $24,5 / 24,3$, respectivamente para os teores de $1,5 \%, 3 \%, 6 \%$ e $12 \%$. Isso evidencia que polímeros de mesma base podem apresentar resultados e comportamentos muito distintos, conforme sua propriedade tensoativa ou sua composição com outros agentes pela indústria, que inibam ou diminuam possível formação de microbolhas e incorporação de ar. 
Figura 6 - Resistência à compressão axial (a) e módulo de deformação (b) aos 28 dias das argamassas modificadas com EVA

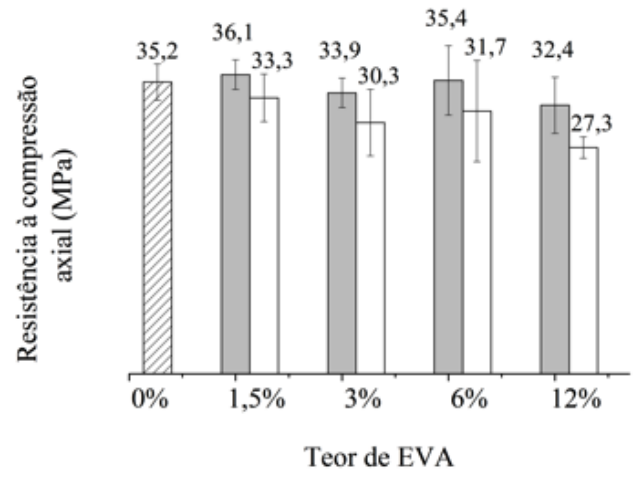

(a)

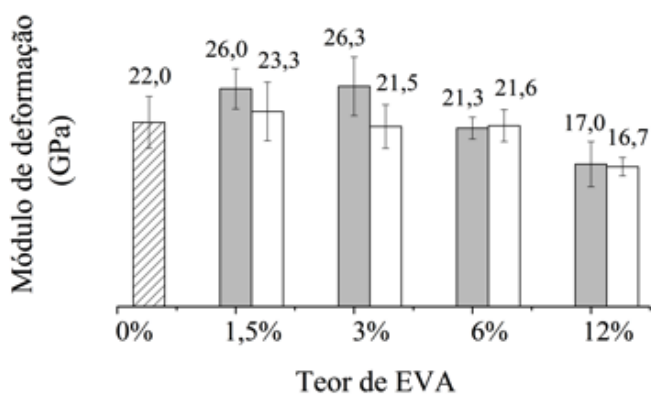

(b)

Nota: Legenda:

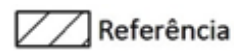

Polímero A

Polímero B

Como observado na literatura, as argamassas modificadas com polímeros possuem pelo menos 3\% a mais de ar incorporado quando comparadas às argamassas convencionais (GEIST; AMAGNA; MELLOR, 1953). O aumento da porosidade interna com a adição de polímero pode diminuir a resistência dos compósitos, porém a selagem dos poros pela formação do filme polimérico contribui para a diminuição da permeabilidade da argamassa, que, por sua vez, colabora para o aumento da durabilidade do material. Outro fator que também pode influenciar diretamente o desempenho mecânico das argamassas modificadas é sua condição de cura (úmida, térmica ou ambiente) (RAMLI; TABASSI, 2012). Neste trabalho, optou-se pela cura ambiente mais adequada para a condição de estudo.

\section{Microscopia óptica}

A análise microscópica confirmou a formação do filme polimérico pela presença de EVA nos poros das argamassas modificadas. As imagens de microscopia óptica foram realizadas após o período de 28 dias e mostraram que o aumento do teor de polímero aumenta a selagem dos poros. As argamassas sem adição apresentaram grande quantidade de vazios, resultando em um material mais poroso (Figura 7). Isso explica o alto valor dos resultados de absorção para esse tipo de argamassa.

Nas argamassas modificadas pode-se observar a presença de EVA preenchendo vazios do material (Figuras 8 e 9). Devido à ação surfactante existente no polímero, espera-se que haja incorporação de ar durante a mistura, por conta da dispersão das partículas poliméricas, resultando, assim, em maior porosidade. Isso justifica os menores valores dos resultados de resistência mecânica das argamassas modificadas; no entanto, a presença de polímero favorece a durabilidade do material. Contudo, a adição de polímero possibilitou a formação de poros menores, em conformidade com o apresentado por Gomes, Ferreira e Fernandes (2005). A presença de EVA se torna mais perceptível conforme aumenta seu teor. Isso se dá devido à formação do filme polimérico durante o processo de hidratação do cimento, em que as partículas poliméricas se coalescem e preenchem os poros existentes.

As argamassas modificadas com o polímero B (Figura 9) apresentaram maior número de poros quando comparadas às argamassas modificadas com o polímero A. Isso justifica os valores de resistência à compressão, em que as argamassas modificadas com o polímero B mostraram menor resistência.

\section{Conclusão}

Os polímeros EVA são capazes de influenciar e modificar as propriedades das argamassas convencionais. As argamassas modificadas apresentam maior plasticidade no estado fresco, devido ao menor atrito entre os grãos, garantindo, assim, melhor trabalhabilidade. No estado endurecido, a redução do módulo de deformação da argamassa modificada foi mais pronunciada no teor de $12 \%$, induzindo a uma possível melhoria em sua capacidade de absorção de energia, característica importante para as argamassas de reparo, bem como em sua aderência ao substrato, não estudada neste trabalho.

A adição dos copolímeros em altos teores, como os estudados, pode diminuir a resistência à compressão da argamassa, possivelmente devido ao aumento do teor de ar incorporado, aumentando sua porosidade, 
especialmente vazios com diâmetros na faixa de $100 \mu \mathrm{m}$ a $1 \mathrm{~mm}$, o que pode prejudicar sua aplicação em reparos estruturais. Tal propriedade pode ser compensada por meio da redução da relação água/cimento e uso concomitante com outros aditivos. A redução na absorção de água é proporcional ao aumento do teor de EVA, que pode acarretar maior estanqueidade e durabilidade das argamassas diante de agentes químicos. O filme polimérico que envolve as partículas cimentícias é o responsável pela menor permeabilidade do compósito, podendo também influenciar positivamente sua durabilidade.

Figura 7 - Microscopia óptica da argamassa sem adição

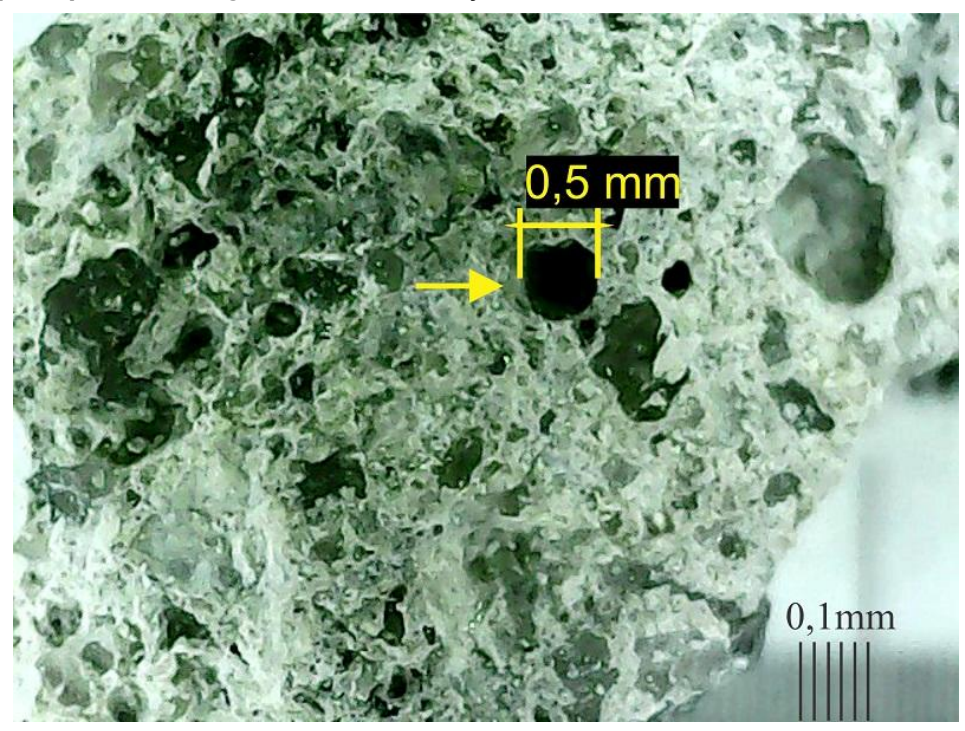

Figura 8 - Microscopia óptica da argamassa modificada com o polímero A em diferentes teores após 28 dias

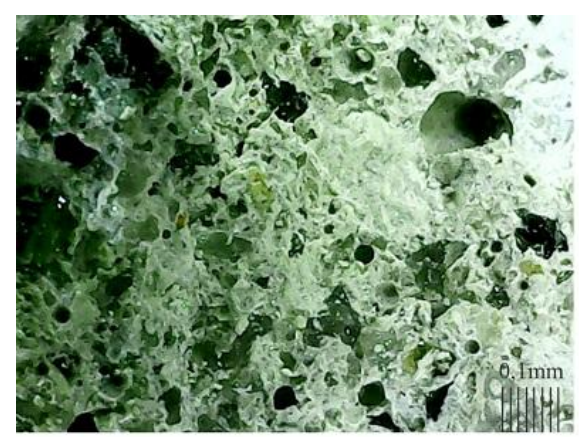

a) $1,5 \%$ de EVA

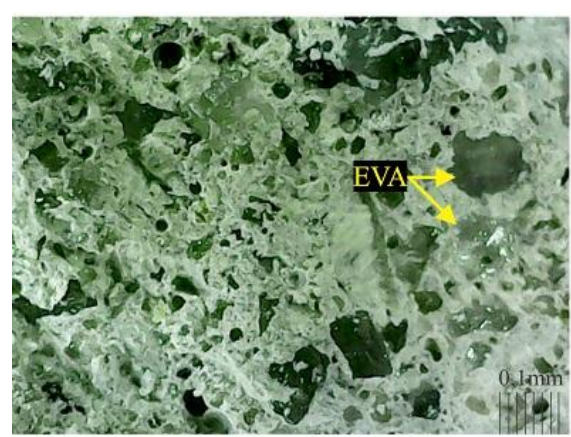

c) $6,0 \%$ de EVA

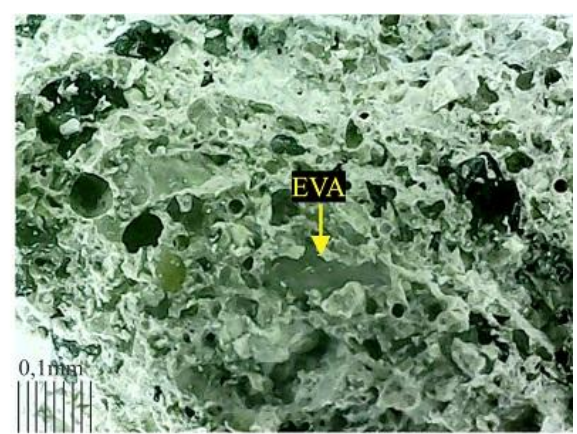

b) $3,0 \%$ de EVA

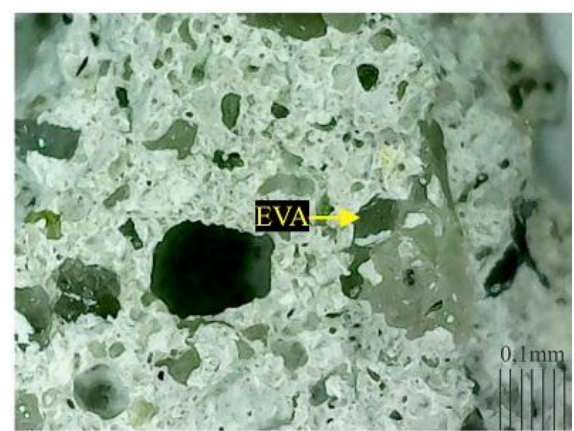

d) $12 \%$ de EVA 
Figura 9 - Microscopia óptica da argamassa modificada com o polímero B em diferentes teores após 28 dias

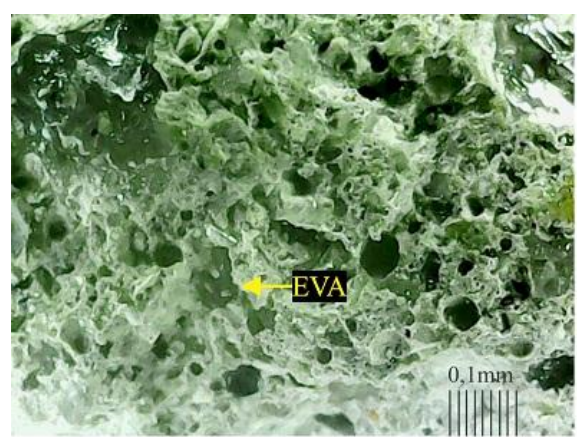

a) $1,5 \%$ de EVA

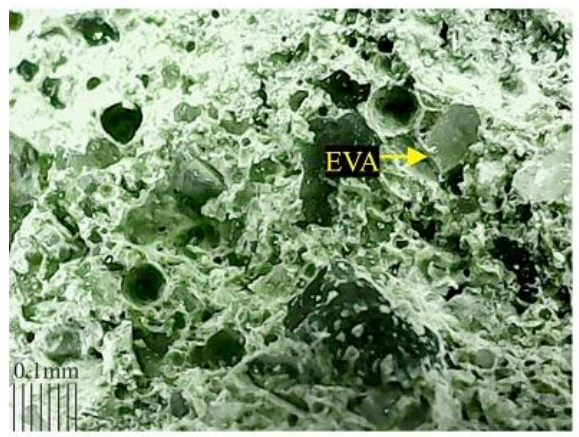

c) $6,0 \%$ de EVA

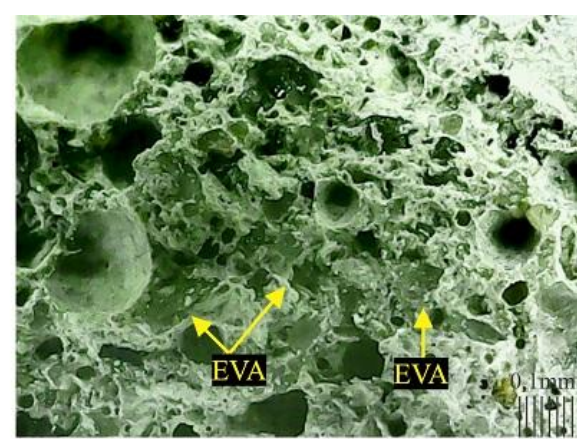

b) $3,0 \%$ de EVA

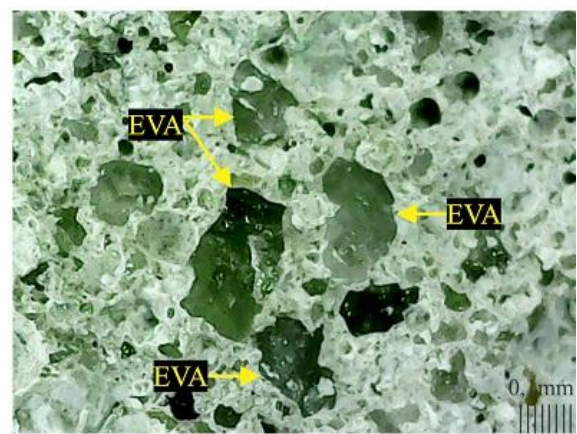

d) $12 \%$ de EVA

As imagens de microscopia óptica indicam a presença do polímero nos vazios existentes, mostrando que os poros foram selados. Além disso, constatou-se, por análises de microscopia, que a presença do polímero nas argamassas tende a melhorar a interface da matriz com os agregados, contribuindo para menor fissuração e, consequentemente, melhor desempenho do compósito.

Pelas propriedades apresentadas, a modificação de argamassas por meio do EVA pode ser considerada uma alternativa potencial para argamassas de reparo em estruturas de concreto, especialmente em pisos ou pavimentos, aplicações em que menor permeabilidade e maior flexibilidade são necessárias.

\section{Referências}

AFRIDI, M. U. K. et al. Development of polymer films by the coalescence of polymer particles in powdered and aqueous polymer-modified mortars. Cement and Concrete Research, v. 33, n. 11, p. 1715-1721, Nov. 2003.

AHMED S. F. U. Mechanical and durability properties of mortars modified with combined polymer and supplementary cementitious materials. Journal of Materials in Civil Engineering, v. 23, n. 9, p. 13111319, Set. 2011.

ASSOCIAÇÃO BRASILEIRA DE NORMAS TÉCNICAS. NBR 7215: cimento Portland: determinação da resistência à compressão. Rio de Janeiro, 1997.

ASSOCIAÇÃO BRASILEIRA DE NORMAS TÉCNICAS. NBR 8522: concreto: determinação do modo estático de elasticidade à compressão. Rio de Janeiro, 2017.

ASSOCIAÇÃO BRASILEIRA DE NORMAS TÉCNICAS. NBR 9778: argamassa e concreto endurecidos: determinação da absorção de água, índice de vazios e massa específica. Rio de Janeiro, 2009.

ASSOCIAÇÃO BRASILEIRA DE NORMAS TÉCNICAS. NBR 13276: vargamassa para assentamento e revestimento de paredes e tetos: determinação do índice de consistência. Rio de Janeiro, 2016.

BETIOLI, A. M. et al. Effect of EVA on the fresh properties of cement paste. Cement and Concrete Composites, v. 34, n. 2, p. 255-260, Feb. 2012. 
GEIST, J. M.; AMAGNA, S. V.; MELLOR, B. B. Improved Portland cement mortars with polyvinyl acetate emulsions. Industrial \& Engineering Chemistry, v. 45, n. 4, p. 759-767, Apr. 1953.

GOMES, C. E. M.; FERREIRA, O. P.; FERNANDES, M. R. Influence of vinyl acetate-versatic vinylester copolymer on the microstructural characteristics of cement pastes. Materials Research, v. 8, n. 1, p. 51-56, Mar. 2005.

MARANHÃO, F. L.; JOHN, V. M. Bond strength and transversal deformation aging on cement-polymer adhesive mortar. Construction and Building Materials, v. 23, n. 2, p. 1022-1027, Feb. 2009.

MEDEIROS, M. H. F.; HELENE, P.; SELMO, S. Influence of EVA and acrylate polymers on some mechanical properties of cementitious repair mortars. Construction and Building Materials, v. 23, n. 7, p. 2527-2533, July 2009.

MEHTA, P. K.; MONTEIRO, P. J. M. Concreto: microestrutura, propriedade e materiais. 2. ed. São Paulo: Ibracon, 2014.

OHAMA, Y. Handbook of polymer-modified concrete and mortars: properties and process technology. New Jersey: William Andrew, 1995.

OHAMA, Y. Polymer-based admixtures. Cement and Concrete Composites, v. 20, n. 2-3, p. 189-212, Jan. 1998.

RAMLI, M.; TABASSI, A. A. Effects of polymer modification on the permeability of cement mortars under different curing conditions: a correlational study that includes pore distributions, water absorption and compressive strength. Construction and Building Materials, v. 28, n. 1, p. 561-570, Mar. 2012.

RAMLI, M.; TABASSI, A. A.; HOE, K. W. Porosity, pore structure and water absorption of polymermodified mortars: an experimental study under different curing conditions. Composites Part B:

Engineering, v. 55, p. 221-233, Dec. 2013.

RIBEIRO, M. S. S.; GONÇALVES, A. F.; BRANCO, F. A. B. Styrene-butadiene polymer action on compressive and tensile strengths of cement mortars. Materials and Structures, v. 41, n. 7, p. 1263-1273, Aug. 2008.

SAKAI, E.; SUGITA, J. Composite mechanism of polymer modified cement. Cement and Concrete Research, v. 25, n. 1, p. 127-135, Jan. 1995.

SILVA, D. A.; ROMAN, H. R.; GLEIZE, P. J. P. Evidences of chemical interaction between EVA and hydrating Portland cement. Cement and Concrete Research, v. 32, n. 9, p. 1383-1390, Sep. 2002.

SILVA, D. A. da; ROMAN, H. R. Caracterização microestrutural de pastas de cimento aditivadas com polímeros HEC e EVA. Ambiente Construído, Porto Alegre, v. 2, n. 2, p. 31-46, abr.jun. 2008.

SU, Z.; SUJATA, K. The evolution of the microstructure in styrene acrylate polymer-modified cement pastes at the early stage of cement hydration. Advanced Cement Based Materials, v. 3,p. 87-93, 1996.

WACKER. Technical data sheet for vinnapas 5044 N. Germany, 2011. Disponível em: https://www.wacker.com/h/en-us/dispersible-polymer-poeder/vinnapas-5044-n-ger/p/000010668. Acesso em: 24 out. 2017.

WANG, R.; WANG, P.-M. Action of redispersible vinyl acetate and versatate copolymer powder in cement mortar. Construction and Building Materials, v. 25, n. 11, p. 4210-4214, Nov. 2011.

WENG, T.-L. Evaluation of cementitious repair mortars modified with polymers. Advances in Mechanical Engineering, v. 9, n. 1, p. 1-7, Jan. 2017.

\section{Agradecimentos}

Agradecemos à Capes pela bolsa de estudos concedida. 


\section{Karen Sorgi Bomediano}

Departamento de Arquitetura e Construção | Universidade Estadual de Campinas | Rua Saturnino de Brito, 224 | Campinas - SP - Brasil | CEP 13083-889 | Tel.: (19)3521-2365 | É-mail: karensorgi@hotmail.com

\section{Carlos Eduardo Marmorato Gomes}

Departamento de Arquitetura e Construção | Universidade Estadual de Campinas | Tel.: (19)3521-2366 | E-mail:

cemgomes@fec.unicamp.br

\section{Patrícia Stella Pucharelli Fontanini}

Departamento de Arquitetura e Construção | Universidade Estadual de Campinas | Tel.: (19)3521-2430 | E-mail: patrícia@fec.unicamp.br

\section{Ambiente Construído}

Revista da Associação Nacional de Tecnologia do Ambiente Construído

Av. Osvaldo Aranha, $99-3^{\circ}$ andar, Centro

Porto Alegre - RS - Brasil

CEP $90035-190$

Telefone: +55 (51) 3308-4084

Fax: +55 (51) 3308-4054

www.seer.ufrgs.br/ambienteconstruido

E-mail: ambienteconstruido@ufrgs.br

\section{(c) (7)}

This is an open-access article distributed under the terms of the Creative Commons Attribution License. 